\title{
AS DISPUTAS POR MEMÓRIA E O ENSINO DA HISTÓRIA INDÍGENA: UM ESTUDO COMPARATIVO DE MANUAIS ESCOLARES
}

\author{
THE MEMORY DISPUTES AND TEACHING INDIGENOUS \\ HISTORY: A COMPARATIVE STUDY OF SCHOOL MANUALS
}

\author{
Martha Victor Vieira ${ }^{1}$
}

\begin{abstract}
RESUMO
Neste artigo pretende-se comparar as representações dos indígenas feitas pelos manuais escolares brasileiros e portugueses. Para realizar esse estudo, selecionamos quatro manuais, que circularam nas escolas desses países entre 2014 e 2017, buscando analisar as narrativas relativas aos primeiros contatos interétnicos no Brasil. O objetivo desse estudo é refletir sobre como a gestão da memória e as questões político-ideológicas, reivindicadas por grupos que pleiteiam o empoderamento, podem interferir nas diretrizes educacionais e nas narrativas dos livros didáticos.
\end{abstract}

\section{PALAVRAS-CHAVE}

Livros Didáticos; Disputas de Memória; Ensino de História.

\begin{abstract}
This article aims to compare the representations of indigenous people made by Brazilian and Portuguese textbooks. To carry out this study, we selected four manuals, that circulated in schools in these countries between 2014 and 2017, and we seek to analyze the narratives related to the first interethnic contacts in Brazil. The aim of this study is to reflect on how memory management and political-ideological issues, claimed by groups that claim empowerment, can interfere with educational guidelines and textbook narratives.
\end{abstract}

\section{KEYWORDS}

Textbooks; Memory Disputes; History teaching.

\footnotetext{
${ }^{1}$ Mestre em História pela Universidade Estadual Paulista, Campus de Franca. Doutora em História Social pelo Instituto de Filosofia e Ciências Sociais, da Universidade Federal do Rio de Janeiro e pós-doutora pela Universidade de Aveiro-Portugal.. Professora do Curso de História, do Programa de Mestrado Profissional em Ensino de História e do Programa de Pós-Graduação em Estudos de Cultura e Território da Universidade Federal do Tocantins, câmpus de Araguaína.
} 


\section{Introdução}

As percepções e ações humanas, costumeiramente, são norteadas pelas experiências e aprendizados que foram adquiridos ao longo das gerações, em determinados tempos históricos e espaços geográficos (ELIAS, 1998, p. 34). Na contemporaneidade, o conjunto de saberes de um indivíduo está relacionado à sua formação familiar, religiosa e escolar, bem como à maneira como esse indivíduo, em sua singularidade, se apropriou desse aprendizado formal e do conjunto de saberes práticos e informais que teve acesso, seja por meio das diferentes mídias, seja por meio das suas redes de sociabilidade. Tanto no âmbito formal quanto informal, tanto nos espaços públicos quanto nos ambientes privados, as identidades individuais são formadas pelas representações simbólicas veiculadas pelos respectivos grupos sociais, aos quais os indivíduos pertencem e nos quais se reconhecem. Importante lembrar, como demonstra Kathryn Woodward (2000), que essas identidades são relacionais, mutáveis e heterogêneas.

O conjunto de experiências e expectativas que um sujeito possui e que contribui para formar a sua identidade e sua visão de mundo advém, portanto, das suas referências culturais, as quais são adquiridas por meio da educação formal e informal. Com as novas tecnologias, há um grande autodidatismo, que tem contribuído, positivamente, para o desenvolvimento do intelecto e do espírito crítico. Mas, por outro lado, os novos ambientes virtuais de interação, criados pela internet, pode tornar as pessoas mais suscetíveis às fake news e aos haters e também promover a expansão de "identidades nãorazoáveis", para usar um termo de Luis Fernando Cerri (2011, p. 112). Segundo esse autor, seriam exemplos de "identidades não-razoáveis", o fundamentalismo religioso ou o nacionalismo exacerbado.

Ao discorrer sobre a relação entre o sistema de ensino e de pensamento, Pierre Bourdieu afirma que um intelectual participa da sua sociedade e da sua época "por meio de suas aprendizagens intelectuais e, em especial, por sua formação escolar." (BOURDIEU, 2005, p. 210). De fato, não obstante a ampliação e variedade dos espaços de debates e formação de opinião existente nas redes sociais, a instituição escolar, de nível 
superior e básico, continua a ser, por excelência, um local de aquisição de capital cultural referendado pelo poder público e pela sociedade. Nesse sentido, as instituições de ensino constituem um espaço de sociabilidade, debate e aprendizado que pode servir tanto como instrumento de homogeneização e reprodução das relações desiguais entre os seres humanos, como aponta Pierre Bourdieu (2005), quanto para despertar as sensibilidades nos estudantes, visando à construção de um mundo melhor para todos e todas.

Nessa linha de raciocínio, pode-se dizer que a escola consiste em um importante espaço não somente por socializar capital cultural ${ }^{2}$ e uma memória social, mas também para se discutir questões políticas e sociais e, quiçá, sugerir intervenções para o poder público, em prol da comunidade. A despeito dessa importante função social, a educação formal não pode ser vista como o oráculo que irá responder todas as nossas perguntas ou mesmo uma panaceia nacional, que irá sanar os males existentes na contemporaneidade. Outras instituições da sociedade civil organizada (partidos, sindicatos, associações, imprensa, ONGs etc) precisam atuar de forma responsável e ética para que se possa construir uma sociedade menos desigual, mais democrática e humanizada.

Particularmente, ao ensino de história, nos cursos de nível superior e básico, compete produzir e fazer circular o conhecimento produzido na academia, sem negligenciar a importância dos saberes pertencentes aos povos tradicionais e das pessoas comuns. Compete ainda cultivar valores democráticos e humanitários, promover o respeito à diferença, incentivar a tolerância e discutir deveres e direitos. Sobretudo, entendo que o ensino de história deve contribuir para o desenvolvimento do discernimento crítico, em relação às representações enunciadas no passado e no presente, que objetivam justificar determinadas ações iníquas e unilaterais. Neste artigo, ao fazer uma comparação entre os livros didáticos brasileiros e portugueses, no que tange ao conteúdo relativo aos primeiros contatos interétnicos ocorridos no século XVI, objetivase destacar como as narrativas dos livros didáticos podem servir para invisibilizar ou dar protagonismo aos povos indígenas, por meio das representações que eles veiculam.

\footnotetext{
2 Para Pierre Bourdieu (1996), o capital cultural está associado ao conhecimento reproduzido nas instituições escolares, que contribui para a instituição das fronteiras sociais.
} 


\section{A historiografia da expansão portuguesa e as disputas de narrativas}

Fazendo uma análise comparativa en passant da historiografia sobre o período colonial no Brasil e em Portugal, nota-se que os historiadores desses dois países possuem um produtivo diálogo acadêmico, reverberado em coletâneas, produzidas desde meados dos anos de 1980, que circulam nos dois lados do Atlântico, contendo textos tanto de pesquisadores portugueses quanto brasileiros. Dentre essas coletâneas estão: a Nova história da expansão portuguesa: Império luso-brasileiro, 1750-1822 (SERRÃO; MARQUES, 1986); História da expansão portuguesa, 1697-1808 (BETHENCOURT; CHAUDHURI, 1998); Dicionário da História da Colonização Portuguesa no Brasil (SILVA, 1994); Modos de governar: ideias e práticas políticas no Império Português, séculos XVI a XIX (BICALHO; FERLINI, 2005); Linguagens e fronteiras do poder (CARVALHO, et al, 2011), entre outras.

$\mathrm{O}$ diálogo entre os estudiosos portugueses e brasileiros tem sido ampliado pela internet, que possibilita que o conhecimento circule com mais facilidade, sobretudo, devido à quantidade de periódicos com acesso aberto e aos frequentes Congressos, onde se divulgam as pesquisas realizadas, sendo algumas coletâneas resultados das comunicações apresentadas.

No que diz respeito à história do contato interétnico, a produção historiográfica lusa e brasileira tem destacado tanto os conflitos quanto as negociações ocorridas entre os povos pré-cabralianos e os colonizadores. Ao tratar da dimensão do conflito, os historiadores, no geral, abordam o processo de conquista do território, a escravidão indígena, as guerras interétnicas, estimuladas pelos europeus, as resistências ao modo capitalista de produção e a violência simbólica, ocasionada pela introdução do cristianismo. No que tange a negociação, ressalta-se o protagonismo indígena, apontamse as alianças feitas com os colonizadores para combater o inimigo externo, aborda-se a contribuição dos indígenas aliados para o êxito da empresa colonial e realizam-se inferências sobre o perspectivismo ameríndio, conforme se pode notar nos estudos de Eduardo Viveiros de Castro (1996, p. 124).

Apesar de a produção historiográfica sobre a América portuguesa caminhar pari passu em Portugal e no Brasil, nota-se que, em relação aos livros didáticos, há uma menor atualização historiográfica dos manuais portugueses em relação à história do contato com 
os ameríndios, ocorrida ao longo do período colonial, na medida em que esses manuais minimizam o protagonismo indígena neste empreendimento. No Brasil, convém lembrar, que é recente a ênfase dada nos livros didáticos em relação à temática indígena. Mas, já nos finais dos anos de 1980, observa-se uma revisão das narrativas didáticas tradicionais e uma crítica feita ao eurocentrismo (VIEIRA, 2018).

A partir da Lei 11.645/2008, que torna obrigatória o ensino da história e cultura indígena, houve um aumento significativo das produções sobre os povos tradicionais do Brasil. Essa política educacional voltada para a promoção e valorização da diversidade étnica e as exigências dos editais do PNLD (Plano Nacional do Livro Didático) para que os manuais contemplem as legislações brasileiras parecem-me ser uma das razões da diferença nas narrativas dos manuais portugueses e brasileiros em relação à história do contato. Afinal, como afirma Tânia Regina de Luca (2009, p. 151), os manuais didáticos revelam, além das práticas pedagógicas e o grau de desenvolvimento do conhecimento científico, "as expectativas, valores e crenças vigentes na sociedade em que foram produzidos". Mais especificamente, o conteúdo dos livros didáticos é influenciado pelas finalidades educativas que são reivindicadas pela sociedade e por seus representantes, que possuem poder de mando no âmbito do aparato estatal (CHERVEL, 1990; LUCA, 2009; VIEIRA, 2018).

Desse modo, pode-se dizer que a dissonância entre os manuais brasileiros e portugueses, no tocante à história do indígena, está diretamente relacionada às políticas educacionais empreendidas pelos Estados nacionais. Pois, em Portugal não há uma demanda social para uma revisão da história contada sobre os povos pré-cabralinos, contudo, há estudos sobre os manuais que criticam a forma como é tratada a história do contato entre portugueses e africanos. As pesquisas de Marta Araújo e Sílvia Maeso (2013, p. 152-154), sobre a questão étnica, indicam que em Portugal essa reflexão tem feito parte do cotidiano dos professores de história, mas, na visão das autoras, ainda se observa nos manuais didáticos um "silêncio" sobre a questão racial.

Ora, como afirma Raimundo Cuesta Fernández (1997, p. 107): “Todo curriculum implica uma selección cultural", sendo as instituições responsáveis pela estrutura curricular ligadas ao sistema educativo dos respectivos Estados. Em outros termos, muito embora, na atualidade, haja uma escuta dos professores, ao fim e ao cabo, são agentes autorizados pelo aparato estatal, que ratificam ou não qual conhecimento é "legitimo" 
para ser ensinado, sobretudo, na educação básica. Como a cultura é heterogênea e os governos sofrem mudanças, as políticas educacionais e os currículos são definidos num campo de disputas de interesses e visões de mundo.

No Brasil, a partir dos anos de 1980, por exemplo, muitos movimentos sociais e intelectuais passaram a demandar uma revisão das representações que circulavam sobre as mulheres, descendentes de africanos e indígenas, a fim de reduzir o preconceito racial e de gênero, por isso, na contemporaneidade, busca-se contemplar essas temáticas no currículo escolar, havendo, inclusive, a obrigatoriedade do ensino da história e cultura africana e indígena. Como essas demandas não são consensuais, há constantes debates, atualizações e revisões feitas dos livros didáticos, cujas narrativas, por fazerem uma gestão da memória e do esquecimento, são frequentemente contestadas e questionadas.

As narrativas dos livros didáticos revelam, além das escolhas metodológicas e epistemológicas, o projeto político vigente e as disputas existentes no contexto de produção e circulação da obra. Christian Laville (1999) ilustra muito bem como a guerra das narrativas sobre o ensino de história foi feita em vários países europeus e nos Estados Unidos, gerando intensos debates no campo político e entre o professorado, a partir dos anos de 1970. Na opinião deste educador: "A história é certamente a única disciplina escolar que recebe intervenções diretas dos altos dirigentes e a consideração ativa dos parlamentos. Isso mostra quão importante é ela para o poder.” (LAVILLE, 1999, p. 130).

As demandas de reescrever as narrativas históricas ocorrem porque os dirigentes querem fazer uma gestão da memória oficial para justificar uma mudança política significativa alcançada (POLLAK, 1989) ou então porque determinados grupos, seja de direita ou de esquerda, com poder de agenda sobre o Estado, as editoras ou as diferentes mídias, pretendem fazer uso dos fatos históricos com finalidades político-ideológicas para conquistar a hegemonia almejada. É interessante dizer que até mesmo movimentos ditos "sem partido" possuem um posicionamento, que se quer mascarar sob um discurso revisionista e de uma educação imparcial e apolitizada.

\section{Os indígenas nos manuais escolares portugueses e brasileiros}

Tanto no Brasil quanto em Portugal a presença nos manuais escolares de uma visão etnocêntrica em relação à época colonial contribui para perpetuar uma memória 
histórica que enfatiza o eurocentrismo. Essa memória nos foi legada pelos primeiros registros feitos por missionários, cronistas e agentes estatais, os quais representavam os indígenas como selvagens, que detinham costumes exóticos. Desse modo, o seu protagonismo, sua atuação como sujeito histórico, não somente como inimigo, mas como aliado do colonizador foi esmaecida (OLIVEIRA; ALMEIDA, 2016, p. 10), na medida em que se difundiu uma visão maniqueísta do contato. Ademais, os primeiros registros coloniais também simplificaram as informações relativas aos grupos contatados, definindo-os como Tupis e Tapuias, ocultando assim a diversidade cultural e linguística desses povos (MONTEIRO, 1994, p. 432).

Como afirma Caio Boschi (1998, p. 388), a visão que temos dos indígenas ainda “é unilateral, posto que esse universo nos chegou pela óptica do relato do colonizador branco, o qual, por certo, não se afastou dos parâmetros culturais europeus para descrever o mundo histórico do nativo".

O primeiro relato eurocêntrico, que é muito usado nos manuais didáticos brasileiros e portugueses, é a Carta Pero Vaz de Caminha, que descreve o indígena como dócil e propenso a ser cristianizado. Igualmente, encontram-se nos manuais imagens retiradas dos propalados relatos de Hans Staden, presentes no livro Duas Viagens ao Brasil (1557), no qual o indígena foi representado como um selvagem, que agia violentamente e praticava a antropofagia. Outro documento recorrente nos manuais didáticos é a imagem que representa os indígenas cortando e carregando madeira, que foi retirada do Atlas Miller, também conhecido como Atlas Lopo Homen-Reineis, produzido em 1519.

Ao analisar o conteúdo do manual Novo HGP 5: História e Geografia de Portugal (2016) e Máquina do Tempo 5 (2017), notamos que nesses manuais ressalta-se o protagonismo português e a herança cultural deixada ao Brasil. Narra-se que, nos primeiros contatos, os indígenas agiram de forma pacífica, mas no decorrer do tempo tornaram-se agressivos.

No Novo HGP 5 (2016) encontram-se quatro documentos que tratam da história do contato entre o colonizador português com os indígenas, quais sejam: a Carta de Pero Vaz de Caminha, uma imagem do Atlas de Lopo Homem, a Carta do padre José de Anchieta e uma ilustração de uma aldeia, onde aparecem indígenas e missionários. Seguindo à risca a leitura da Carta de Pero Vaz de Caminha aponta-se que, no Brasil, os 
portugueses teriam contatado os indígenas que se organizavam em tribos, faziam caça, pesca e coleta. Esses povos, segundo os autores, viviam nus, pintavam-se e usavam penas de aves: "Não se lhes conhecia qualquer religião e adoravam as forças da natureza. Eram pacíficos. Inicialmente, receberam bem os portugueses - ofereceram-lhes comida e os dois povos conviveram" (MATIAS; OLIVEIRA; CANTANHEDE, 2016, p. 150). Notase que a dimensão conflituosa da expansão portuguesa e da conquista territorial é nitidamente minimizada nesse livro didático, que ainda reproduz uma visão oficial deste contexto histórico.

Nas laterais do Novo HGP 5 há perguntas relacionadas às informações que se deve procurar no texto. Há vários mapas, explicações sintéticas sobre os sentidos de algumas palavras chaves, tais como: expansão, carta náutica, colonização, missionação etc. No final do livro há uma cronologia histórica que abrange de 1094 a 1668 e um quadro dos reis e rainhas de Portugal do século XII a XVII. Todo tópico abordado conta ainda com um quadro intitulado "Relembra", que faz um resumo das principais informações do tópico anterior.

Neste manual, os exercícios sugeridos buscam levar o aluno a pensar no significado das palavras, fazer pesquisa fora dos manuais, problematizarem os documentos e a refletirem sobre o impacto cultural da expansão ultramarina. Procura-se também usar o conhecimento que o aluno possui no presente para levá-lo a refletir sobre o passado.

O livro Máquina do Tempo 5 (2017) possui um formato e métodos um pouco diferente do Novo HGP 5, mas o conteúdo dos manuais é semelhante, visto acompanharem as metas curriculares nacionais para o ensino das disciplinas de história e geografia de Portugal. Neste manual, aponta-se que no Brasil os portugueses encontraram uma fauna e flora exótica e "várias tribos de índios", que viviam da caça coleta e pesca. Muitos colonos teriam constituído "família com as mulheres locais", dando origem aos mamelucos. Os missionários, especialmente jesuítas, teriam levado o cristianismo ao Brasil "convertendo grande parte da população índia" (SOUSA; SOARES; ALBINO, 2017, p. 114).

Nas perguntas feitas aos estudantes há uma problematização crítica do conteúdo quando se relembram quem os portugueses encontraram no Brasil e quem eram os "trabalhadores" (indígenas e africanos). Pede-se ainda para fazer um relato, inspirado em 
Caminha, de um índio descrevendo um português. Em outra sugestão de redação, instigase a falar de três aspectos positivos e um negativo sobre o contato interétnico ocorrido no século XVI (SOUSA; SOARES; ALBINO, 2017).

A presença dos mapas e de ilustrações visuais (de objetos, paisagens e pessoas) relativas às informações do texto possibilita maior compreensão do mesmo. Os mapas fazem referências às viagens, às rotas comerciais e aos tratados. Exercícios para a associação das informações e de completar frases ajudam a reforçar o conteúdo. Nomes e datas importantes são realçados em negrito. Particularmente, interessante é a sugestão de elaborar um texto escrito a partir de um dado acontecimento ou uma ideia envolvendo personagens históricos sugerido pelos autores. A proposição de elaborar questões sobre as imagens cartográficas estimula a interatividade e o raciocínio.

Mas não se menciona, por exemplo, a discussão feita pelo historiador português Joaquim Romero Magalhães (1998), que o contato não gerou apenas um "hibridismo cultural", na medida em que a mão de obra indígena era muito requisitada e foi motivo de intensa disputa desde os primeiros tempos de colonização. Igualmente, não se faz menção que o contato foi bastante nocivo para a cultura ameríndia, pois os aldeamentos contribuíram para a "desintegração das comunidades indígenas" e da "cultura nativa". As aldeias foram úteis ao projeto colonizador tanto para socialização e conversão indígena quanto para servir como fornecedor de mão de obra para os colonos (BOSCHI, 1998, p. 394).

Em relação aos manuais brasileiros, tomando como parâmetro o conteúdo de alguns manuais aprovados no PNLD 2017, destinados ao sétimo ano, do ensino fundamental, observa-se que a defasagem "entre o conhecimento que circula nas Universidades e o ensino de história na educação básica diminuiu, mas ainda permanece" (VIEIRA, 2018, p. 204).

O manual História.doc 7, de autoria dos historiadores Ronaldo Vainfas, Jorge Ferreira, Sheila de Castro Farias e Daniela Buono Calainho (2015), possui uma proposta bastante interessante. Com base na nova história indígena, os autores enfatizam as relações de conflito e negociação e o protagonismo de algumas lideranças indígenas, tais como: Cunhambebe, Tibiriçá, Araribóia e Zorobabé. A quantidade de informações sobre os indígenas neste manual é significativa e os autores buscam instigar os professores a 
praticarem a interdisciplinaridade, sugerindo atividades, sobretudo, com o conhecimento geográfico.

Mas, não obstante às exigências do currículo da educação básica em relação à história indígena, ainda se encontram manuais que destacam mais os povos précolombianos do que os pré-cabralinos, como é o caso da obra coletiva Projeto Araribá História 7 (2014), publicada pela editora Moderna, destinada ao sétimo ano. Esse livro didático ainda trata dos primórdios da história do Brasil a partir do colonizador, pois insere a história dos indígenas dentro do tópico sobre as navegações portuguesas. Essa forma de construção narrativa privilegia o eurocentrismo e tem sido reproduzida desde o período colonial, como se nota em boa parte das interpretações históricas construídas até meados do século XX, cuja historiografia enfatizava a história dos heróis e a perspectiva política e econômica.

No concernente às propostas metodológicas, os manuais brasileiros, assim como os portugueses, usam muito as imagens para se trabalhar o conteúdo histórico. A relação entre presente e passado também se encontra na história ensinada no Brasil. Entretanto, na minha avaliação, os manuais portugueses são mais interativos, havendo inclusive um livro de exercício para o aluno, que acompanha o livro didático, algo que não se observa nos manuais brasileiros. Chama atenção também o fato de os manuais brasileiros demonstrarem uma preocupação maior com o professor, havendo inclusive um livro, com informações e sugestões adicionais, feito para auxiliar este profissional no desenvolvimento das aulas.

As representações dos indígenas nos manuais brasileiros, todavia, estão mais condizentes com os estudos atuais, ressaltando-se o processo de conquista territorial, o protagonismo indígena e a diversidade étnica que havia no Brasil na época da chegada dos portugueses.

Uma diferença importante é que, em Portugal, a distribuição dos manuais escolares ainda não é gratuita, como no Brasil (SOLÉ, 2014, p. 61). Outra diferença significativa é que no Brasil a história, como disciplina, consta na matriz curricular no ensino fundamental, separada da geografia. O conteúdo sobre o contato interétnico está nos livros do sétimo ano. Já no currículo de Portugal os alunos estudam essa temática a 
partir do quinto ano, no segundo ciclo ${ }^{3}$. Mas o ensino de história e geografia é ministrado junto, de modo que os manuais trazem conhecimentos das duas disciplinas, com maior ênfase na história. A partir do terceiro ciclo, história e geografia são ensinadas separadamente.

\section{Considerações finais}

$\mathrm{Na}$ análise dos manuais escolares portugueses nota-se que o tema do contato interétnico entre portugueses e ameríndios está contemplado nas narrativas, contudo, há certa distância entre a abordagem historiográfica relativa à época colonial e a história ensinada na educação básica em Portugal. Essa distância, por um lado, é justificável devido à enorme capacidade de síntese que requer a escrita de um livro didático, sobretudo, se considerarmos a vasta literatura que existe sobre a história e a geografia de Portugal das sociedades coletoras até a atualidade, que é o recorte temático recomendado para se ensinar aos estudantes das escolas portuguesas.

No que concerne ao Império português, os autores de manuais didáticos necessitam de um vasto conhecimento, devido à diversidade de povos que foram contatados com a expansão ultramarina. Por outro lado, há de se lembrar que: "Os livros didáticos têm sido, de fato, grandes responsáveis pela permanência de discursos fundadores da nacionalidade" (FONSECA, 2004, p. 73). Isso faz com que haja uma disputa em torno das matrizes curriculares dos Estados nacionais para que se selecionem conteúdos que contribuam para a construção de uma memória positivada do passado. É nesse sentido que muitos agentes estatais, até mesmo seguimentos sociais conservadores, demonstram certo interesse político na produção e circulação de uma narrativa histórica em que as mazelas passadas, envolvendo violência física e simbólica, por parte das instituições, não venham à tona para a sociedade.

O fato é que, tendo em vista o conteúdo dos dois manuais escolares analisados, nota-se que a história ensinada em Portugal apresenta uma narrativa muito próxima da história contada de uma perspectiva oficial, na qual se ressalta as ações missionárias, os feitos dos navegadores e a dimensão econômica da expansão ultramarina, embora haja

\footnotetext{
${ }^{3}$ Em Portugal, o ensino se divide em básico e secundário. O básico possui três ciclos: primeiro ciclo, que vai do primeiro ao quarto ano; o segundo ciclo, que abrange o quinto e o sexto ano; e o terceiro ciclo, que vai do sétimo ao nono ano. $\mathrm{O}$ ensino secundário inicia-se no décimo ano e perfaz um total de três anos.
} 
algumas questões sobre cultura e sociedade. Entretanto, nota-se que os autores tentam contemplar todos os principais temas relativos ao Império português e, sobretudo, notase um empenho em tornar o conhecimento histórico mais próximo da realidade vivida pelo aluno, o que é bastante positivo. Há também vários exercícios que estimulam às competências dos alunos, especialmente, as habilidades de escrita e de argumentação.

Nos manuais brasileiros, por sua vez, nota-se uma tendência em valorizar a história indígena, tratando-a em uma unidade separada e com várias informações, que indicam a diversidade étnica, como faz o livro História.doc 7 (VAINFAS, 2015). O manual intitulado Vontade de Saber História 7 também apresenta um capítulo intitulado "A América Pré-Colombiana" (PELEGRINI; DIAS; GRINBERG, 2015), no qual se aborda os povos indígenas antes da chegada dos espanhóis e portugueses, rompendo com a divisão tradicional dos temas que insere a temática indígena dentro das navegações ultramarinas.

A nova forma de conceber os temas dos manuais escolares brasileiros, certamente, foi estimulada devido às exigências que foram colocadas pelas Leis 10.639/2003 e 11.645/2008, que tornou obrigatória o ensino da história e da cultura africana e indígena. Embora, em 1979, o manual escolar História da Sociedade Brasileira já escrevesse a história do Brasil começando pelos habitantes de "Pindorama" (ALENCAR; CARPI; RIBEIRO, 1985).

Nos manuais brasileiros analisados, pertencentes ao PNLD 2017, se observa ainda um interesse em demonstrar a relação da história com várias disciplinas, literatura, geografia, matemática, filosofia etc, e uma preocupação em instruir e sugerir propostas para o professor da educação básica. Enquanto os manuais portugueses enfatizam mais a relação da história com a geografia e dedicam mais espaço no manual para interagir e sugerir trabalhos para os estudantes.

Acredito que uma das razões das diferenças entre os manuais brasileiros e portugueses pesquisados tem relação com as trajetórias históricas dos respectivos Estados, afinal, "a educação é um poderoso instrumento de legitimação política" (FONSECA, 2004, p. 87) e de formação identitária. Por isso, Laville (1999, p. 132-135) tem razão quando afirma que: "Cada comunidade quer ver a sua própria história contada". E que talvez fosse o caso de se pensar em narrativas "supranacionais", como sugere o educador canadense. No Brasil, por enquanto, o movimento é no sentido de reescrever a 
história para formar e consolidar a identidade do grupo, demarcar as fronteiras socioculturais, reivindicar direitos ou reinterpretar acontecimentos políticos anteriores ao processo de redemocratização, feito após 1980.

Os usos da história com objetivos pragmáticos podem-se notar desde o século XIX no Brasil, quando a história, a literatura, a geografia e a arte foram mobilizadas para contribuir com a formação dos Estados nacionais, fazendo com que as pessoas se identificassem com os mesmos. Esse pragmatismo político implicou na veiculação de uma produção cultural, que construiu uma ideia de nação, mas invisibilizou a história e a cultura da população pluriétnica, que residia no extenso território brasileiro. Por essa razão, esse discurso da identidade nacional e os valores patriarcais que o acompanham são contestados na atualidade pelos movimentos sociais, que defendem maior visibilidade para as mulheres, os indígenas e os descendentes de africanos, haja vista que:

[...] A política de identidade concentra-se em afirmar a identidade cultural das pessoas que pertencem a um determinado grupo oprimido ou marginalizado. Essa identidade torna-se, assim, um fator importante de mobilização política [...] (WOODWARD, 2000, p. 34).

De fato, é notório que todos os agentes sociais que demandam construções e revisões das narrativas históricas partem da premissa do poder das representações históricas para a formação/consolidação das identidades, empoderamento político, garantia de direitos e condicionamento dos padrões comportamentais.

Como resultado de um campo de disputas, as legislações educacionais, tanto em Portugal quanto no Brasil, são oriundas de orientações epistemológicas, demandas sociais e questões ideológicas dos grupos que possuem poder de agenda junto ao Estado. Os manuais escolares de história, como seguem o currículo oficial, são produzidos de acordo com esse jogo de forças, no qual há uma concorrência patente sobre qual memória interessa deixar para as gerações vindouras. Diversos são os agentes envolvidos nessa disputa, enquanto uns reivindicam serem lembrados como protagonistas, outros pleiteiam silêncio, esquecimento e minimizações das ações arbitrárias passadas. 


\section{REFERÊNCIAS}

ALENCAR, Francisco; CARPI; Lucia; RIBEIRO, Marcus Venício. História da Sociedade Brasileira. $3^{a}$ ed. Rio de janeiro: Ao Livro Técnico, 1985.

ARAÚJO, Marta; MAESO, Sílvia Rodrigues. A presença ausente do racial: discursos políticos e pedagógicos sobre história, "Portugal" e (pos-) colonialismo. In. Educar em Revista. Curitiba, n. 47, p. 145-171, jan./mar. 2013. Disponível em: $<$ https://www.scielo.br/scielo.php?pid=S0104-

$40602013000100010 \&$ script=sci_abstract\&tlng=pt $>$. Acesso em 20 nov. 2019.

BETHENCOURT, Francisco; CHAUDHURI, Kirti (Dir). História da expansão portuguesa (1697-1808). Navarra, Espanha: Gráfica Estella, vol. III, 1998.

BICALHO, M. F.; FERLINI, V. L. A. Modos de governar: ideias e práticas no Império português, séculos XVI a XIX. São Paulo: Alameda: 2005.

BOSCHI, Caio. As missões no Brasil. In. BETHENCOURT, Francisco; CHAUDHURI, Kirti (Dir). História da expansão portuguesa (1570-1697). Navarra, Espanha: Gráfica Estella, vol. II, 1998a. p. 388-402.

BOURDIEU, Pierre. A economia das trocas simbólicas. São Paulo: Perspectiva, 2005. CARVALHO, José Murilo, et al (Org.). Linguagens e fronteiras do poder. Rio de Janeiro: FGV, 2011.

CASTRO, Eduardo Viveiros de. Os pronomes cosmológicos e o perspectivismo ameríndio. In. Revista Maná, Rio de Janeiro, vol. 2, n. 2, p. 115-144. 1996. Disponível em: $<$ http://www.scielo.br/scielo.php?script=sci_arttext\&pid=S01049313199600020000 5> . Acesso em 10 nov. 2018.

CERRI, Luis Fernando. Ensino de história e consciência histórica: implicações didáticas de uma discussão contemporânea. Rio de Janeiro: FGV, 2011.

CHERVEL, André. História das disciplinas escolares: reflexões sobre um campo de pesquisa. Teoria \& Educação, n. 2 1990. p. 177-229. Disponível em: $<$ https://moodle.fct.unl.pt/pluginfile.php/122510/mod_resource/content/0/Leituras/Cher vel01.pdf >. Acesso em: 04 fev. 2018.

ELIAS, Norbert. Sobre o tempo. Rio de Janeiro: Zahar, 1998.

FERNÁNDEZ, Raimundo Cuesta. Sociogénesis de uma disciplina escolar: La Historia. Barcelona: Ediciones Pomares-Corredor, S.A. 1997.

FONSECA, Thais Nívia de Lima e. $2^{\text {a }}$ Ed. História \& Ensino de História. Belo Horizonte: Autêntica, 2004. 
LAVILLE, Christian. A guerra das narrativas: debates e ilusões em torno do ensino de História. In. Revista Brasileira de História. São Paulo, v. 19, nº 38, p. 125-138. 1999. Disponível em: $\quad$ http://www.scielo.br/scielo.php?script=sci_arttext\&pid=S0102-

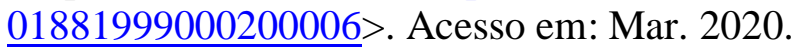

LUCA, Tania Regina de. Livro didático e estado: explorando possibilidades interpretativas. In. ROCHA, Helenice; REZNIK, Luís; MAGALHÃES, Marcelo de Souza (Org.). A história na escola: autores, livros e leituras. Rio de Janeiro: FGV, 2009. p. 151-172

MAGALHÃES, Joaquim Romero. A construção do espaço brasileiro. In. BETHENCOURT, Francisco; CHAUDHURI, Kirti (Dir). História da expansão portuguesa (1570-1697). Navarra, Espanha: Gráfica Estella, vol. II, 1998. p. 28-64.

MATIAS, Ana; OLIVEIRA, Ana Rodrigues; CANTANHEDE, Francisco. Novo HGP 5: História e Geografia de Portugal. $1^{\mathrm{a}}$ ed. $2^{\mathrm{a}}$ tiragem. Lisboa: Texto Editores Lda, 2016. (Revisão científica Maria Helena da Cruz Coelho).

MONTEIRO, John M. Escravidão indígena In. SILVA, Maria Beatriz Nizza da (Coord.). Dicionário da História da Colonização Portuguesa no Brasil. Lisboa/São Paulo: Verbo, 1994. p. 303-306.

OLIVEIRA, João Pacheco de; ALMEIDA, Maria Regina Celestino de. Prefácio. In. WITTMANN, Luísa Tombini; SOUZA, Fabio Feltrin de. Protagonismo indígena na história. Tubarão-SC: Copiart; [Erechim, RS]: UFFS, 2016. p. 7-14. (Educação para as relações étnico-raciais, v. 4). Disponível em: $<$ https://ayalaboratorio.files.wordpress.com/2017/07/vol4-protagonismo-indc3adgenana-histc3b3ria.pdf > . Acesso em: 23 mai. 2018.

PELLEGRINI, Marco; DIAS, Adriana; GRINBERG, Keila. Vontade de saber história 7. $3^{\mathrm{a}}$ ed. São Paulo: FTD, 2015 (PNLD, 2017, Ensino Fundamental II).

Projeto Araribá - História (2014). São Paulo: Moderna, 2014. (Obra organizada pela Editora Moderna. Editora responsável Maria Raquel Apolinário).

POLLAK, Michael. Memória, Esquecimento, Silêncio. Estudos Históricos. Rio de Janeiro, vol.2, n.3, p.3-15, $1989 . \quad$ Disponível em: <http://www.uel.br/cch/cdph/arqtxt/Memoria_esquecimento_silencio.pdf $>$.

SERRÃO, Joel; MARQUES, A.H. Oliveira. Nova história da expansão portuguesa. $O$ Império luso-brasileiro, 1750-1822. Lisboa: Editorial Estampa, vol. VIII, 1986. p. 19-62. (Coor. Maria Beatriz Nizza da Silva, 613p).

SILVA, Maria Beatriz Nizza da (Coord.). Dicionário da História da Colonização Portuguesa no Brasil. Lisboa/São Paulo: Verbo, 1994. p. 303-306.

SOLÉ, Glória. O manual escolar no ensino primário em Portugal: perspectiva histórica e análise do ensino da história através deste recurso didático. In. Ensayos. Revista de la Facultad de Educación de Albacete, nº 29-1, p. 43-64, 2014. 


\section{Araguaína}

SOUSA, Luís; SOARES, Luiz; ALBINO, Malvide. Máquina do tempo 5: História e Geografia de Portugal. $1^{\text {a }}$ ed. $2^{a}$ tiragem. Edições ASA, Editora do Grupo Leya, 2017. (Revisão científica e pedagógica João Gouveia Monteiro).

VAINFAS, Ronaldo; et al. História.doc. São Paulo: Saraiva, 2015.

VIEIRA, Martha Victor. O ensino da história dos indígenas nos livros didáticos e a longevidade do paradigma civilizatório europeu. In. Revista Humanidades \& Tecnologia (FINOM), Ano XIII, N. 17, p. 193-208, 2018.

WOODWARD, Kathryn. Identidade e diferença: uma introdução teórica e conceitual. In. SILVA, Tomás Tadeu da. Identidade e diferença: a perspectiva dos estudos culturais. Petrópolis, Rio de janeiro: Vozes, 2000. p. 7-72. 